[pp. 55-65 ]

Vol. 3(1), Enero-Junio, 2015

http://dx.doi.org/10.15359/rnh.3-1.3

\title{
Las universidades \\ públicas en Costa Rica
}

Public universities in Costa Rica

\author{
Jaime Mora Arias \\ Universidad Nacional, Sede Central \\ Heredia, Costa Rica \\ jaime.mora.arias@una.cr
}

\section{Resumen}

Este artículo ofrece una reseña histórica de las universidades públicas de Costa Rica. Desde los tiempos de la colonia, nuestros gobernantes han dado prueba constante de un elevado interés por la educación pública. Ya para mediados de la segunda mitad del siglo XIX, la enseñanza primaria fue declarada obligatoria, por ley, y costeada por el Estado. Además, antes de finalizado ese siglo, el país contaba con colegios de enseñanza media en tres cabeceras de las provincias del Valle Central, a todas luces, un incuestionable logro en el campo de la instrucción ciudadana. En lo referente a la educación superior, en 1814 se funda la Casa de Enseñanza de Santo Tomás que, en 1843, ya dentro del marco de la vida independiente, es elevada al rango de Universidad y en 1850 reestructurada académicamente para poder responder a las exigencias educativas de la época. La Universidad de Santo Tomás se mantuvo activa hasta 1888, año en el que fue clausurada por no satisfacer los requerimientos educativos del momento. Por largos 52 años, el país adoleció de un centro de educación superior. No fue sino en 1940, año en el que se funda la Universidad de Costa Rica, que se restituye la enseñanza superior. El acelerado crecimiento demográfico del país, a partir de la década de los setenta, ocasiona que la demanda de la matrícula universitaria no fuera atendida satisfactoriamente, lo que da lugar a la aparición de los otros centros de enseñanza superior estatal, Instituto Tecnológico de Costa Rica, la Universidad Nacional, la Universidad Estatal a Distancia y la Universidad Técnica Nacional. 
Palabras clave: Cultura, humanismo, especialización, universidad pública.

\begin{abstract}
This article offers a historical review of Costa Rican public universities. From the very times of the colony until today, our leaders have given constant proof of significant interest in public education. By the middle of the second half of the XIXth century, primary education was declared by law as mandatory and financed by the State. Also, before the end of that century, the country already had secondary education schools in three main cities of the provinces of the Central Valley, evidently an unquestionable achievement in the field of civil education. As for higher education, in 1814 the Casa de Enseñanza de Santo Tomás was founded, which in 1843, already under an independent condition, is raised to the status of University, and, in 1850 it was academically reorganized to be able to meet the educational requirements of the time. The Universidad de Santo Tomás remained active until 1888, when it was closed because it was failing to meet said goal. For fifty-two years, the country lacked a higher-education institution. It was not until 1940, when the University of Costa Rica was founded, that higher education was restored. The intensive demographic growth of the country that started in the decade of the seventies made it impossible for the university to meet the demand of students' registration, which leads to the appearance other state higher education centers, Technological Institute of Costa Rica, the National University, the State Distance University and the National Technical University.
\end{abstract}

Keywords: Culture, humanism, specialization, public university.

\title{
Refiere Teodoro Olarte citado por Karpinsky (1982),
}

La Universidad es una institución -hay que subrayar en su carácter institucional- que, por su esencia, está comprometida a establecer los fundamentos: primero, de una cultura general sólida; segundo, los de una profesión determinada. La profesión, cualquiera que ella sea, ha de ser un injerto practicado en el tallo de una cultura general vivificante. Sólo [sic] así conseguirá la Universidad su fin último: el engendramiento de ciudadanos propiamente cultos. En otras palabras: la Universidad no puede pretender consumar la cultura de cada uno de los que a ella acudan; ella, por exigencia íntima de la misma cultura, tiene que contraerse a cimentar tanto la cultura general como la profesión, porque el trabajo de culturizarse y de profesionalizarse tiene una fecha universitaria de comienzo, pero su término coincide con el término de cada una de las existencias. (p. 19) 
La Universidad es una institución de enseñanza superior que comprende diversos centros educativos (facultades, escuelas, colegios y otros) y confiere los grados académicos correspondientes que, en general, facultan a su poseedor para ejercer una profesión determinada. Según las épocas y naciones, las universidades se estructuran de diferente forma $\mathrm{y}$, aunque el concepto abarca siempre la idea de una organización que ofrece formación de alto nivel, los grados o títulos académicos no siempre se corresponden de forma exacta entre los distintos países. La organización administrativa, la cultura y el poder político han tenido y tienen una relación directa en la aparición de la universidad, en su desarrollo y también en sus crisis.

En el ámbito del conocimiento humano la universidad, como institución académica, emergió como respuesta a la necesidad de orientar y normar la amalgama de conocimientos alcanzados en el campo de la ciencia y la cultura que se dio en Europa a partir de la baja Edad Media y que se conoce con el nombre de pensamiento occidental. A partir de entonces, la universidad se ha constituido en el medio por el cual se desarrolla y se debate el saber, que es lo mismo que decir que es el sello o aval social del conocimiento.

En su larga existencia de casi novecientos años, es necesario destacar el actual perfil que ha moldeado la universidad, muy diferente del de sus orígenes, tan afines a los propósitos de las corporaciones medievales que le sirvieron de modelo. En toda esa prolongada historia, destaca la postura protagónica que, en las dos primeras décadas del siglo anterior, asumió la Universidad de Córdoba, Argentina, orientada a alcanzar la autonomía y democracia de la universidad como institución. Desde entonces, la necesidad y conveniencia social de la universidad se han fortalecido y han resultado incuestionables. A pesar de esto, las dificultades y los cambios de orden político han ocasionado alteraciones en el discurrir diáfano de la vida académica, como consecuencia resultante de la tensión y los desacuerdos entre el poder político y las autoridades educativas.

En lo que corresponde a Costa Rica, también en ese ámbito se han dado roces y desavenencias que han enfrentado a la institución universitaria con el poder políticoeconómico; es justo reconocer que esos desacuerdos no han sido tan extremos como en muchos otros países donde escuelas y facultades han sido clausuradas con la fuerza militar. Aquí la tensión se ha presentado como resultado de las exigencias de los organismos internacionales que imponen las condiciones económicas mundiales mediante disposiciones que entraban y maniataban al Estado. 
La historia de la universidad como institución en Costa Rica se remonta a 1814, año en que se crea La Casa de Estudios de Santo Tomás. Fue esta una institución colonial de enseñanza preparatoria y media con una evidente orientación a satisfacer los fines de la Iglesia Católica. Se impartían allí lecciones de Gramática, Filosofía y Teología con la clara intención de preparar a los jóvenes para la carrera eclesiástica. En los albores de la vida independiente de nuestro país, esta institución fue modernizándose y en 1830 promueve la publicación de un texto titulado: Breves lecciones de aritmética, cuyo autor es el Bachiller Rafael Osejo, Catedrático de esa casa de enseñanza. Vale señalar que este texto es considerado el primer libro impreso en Costa Rica.

Posteriormente, en 1843, durante la primera administración del Dr. José María Castro Madriz, se le confiere a esta casa de enseñanza el título de Universidad de Santo Tomás.

Para 1850, durante el gobierno de Juan Rafael Mora Porras, se da un importante impulso a la universidad con la creación de la Facultad de Medicina y Jurisprudencia. A pesar de este significativo avance, la universidad no pudo librarse de la marcada influencia de la iglesia católica, como resulta evidente cuando en 1853, durante el pontificado del Papa Pío IX, la Universidad de Santo Tomás es declarada Universidad Pontificia, con la consiguiente investidura de los privilegios que tal designación otorgaba.

Como es lógico suponer, este nombramiento honorífico no fue "gratuito", la universidad quedó obligada a impartir las cátedras de religión, teología y enseñanza eclesiástica durante la supervisión del Obispo, quien además tenía la atribución de nombrar los profesores en esas disciplinas, lo mismo que la de autorizar o prohibir la lectura de ciertas obras literarias o científicas.

El presidente Mora aceptó y agradeció el nombramiento pontificio, pero parece que no acató la censura pretendida por el Papa. Para 1858, y siempre en la presidencia de Mora, se publicaron los Estatutos de la Universidad de Santo Tomás, en busca de una renovación.

En esta segunda etapa de la universidad, las cátedras que se impartieron fueron: Teología y Ciencias Políticas, Medicina y Ciencias Naturales. De aquí en adelante, la Universidad sufre un estancamiento que culmina con su clausura en 1888, por recomendación de Mauro Fernández, quien para entonces fungía como Secretario de Instrucción Pública del presidente Bernardo Soto Alfaro. Se consideró que la Universidad no satisfacía los requerimientos y las expectativas 
de la educación superior de ese momento y que se había convertido en una institución inoperante y obsoleta.

El cierre de la máxima casa de enseñanza del país ocasionó que se careciera de una universidad por un largo período de 52 años durante el cual, para acceder a estudios superiores había que salir del país y ese privilegio solo estaba al alcance de las clases adineradas.

No es sino hasta 1940 cuando se restituye en el país la enseñanza superior con la apertura de la Universidad de Costa Rica, en la administración del Dr. Rafael Ángel Calderón Guardia.

De sus ya casi setenta y cinco años de existencia, mucho podría decirse acerca de sus logros así como de sus crisis. Dentro de este contexto, merece mención especial la reforma de 1957, durante la rectoría de Rodrigo Facio Brenes, secundada por varios distinguidos educadores, entre ellos: Enrique Macaya Lahmann, Carlos Monge Alfaro y Abelardo Bonilla Baldares. Fueron precisamente Macaya y Bonilla quienes firmaron la primera propuesta de Reforma Académica ante el Primer Congreso de la Universidad de Costa Rica en 1946, pero que requirió del impulso y de la concreción de un gran rector, como lo fue Facio Brenes, y que vino a significar un modelo nuevo de universidad que modernizó la educación costarricense.

En sus discursos, artículos y mensajes a la comunidad universitaria, siempre dentro de un marco de respeto y admiración por el acierto de los fundadores de la Universidad de Costa Rica, Rodrigo Facio denuncia y analiza los defectos de la institución, al manifestar que esta fue concebida y organizada como una simple agregación de escuelas profesionales antiguas y nuevas sin unidad e identificación y desconectadas de la comunidad, y que este concepto de universidad debía superarse con una nueva perspectiva de la educación superior: la formación de profesionales cultos que tuvieran como base de su especialización una amalgama de conocimientos básicos de la cultura, que los convirtiera en ciudadanos de altos niveles éticos, conscientes de los problemas nacionales y con la mentalidad y el propósito de contribuir, desde diferentes ángulos, a procurarles solución, no profesionales mercantilistas que solo buscan y esperan el medio para lucrar y acumular riquezas, mediante el ejercicio de su profesión.

De acuerdo con este pensar, Albert Einstein, científico judío, nacionalizado estadounidense, manifestó lo que sigue:

No es suficiente enseñar a un hombre una especialización. Por este medio se puede convertir en una especie de máquina útil, pero no en una 
personalidad desarrollada armoniosamente. Es esencial que el estudiante adquiera conocimientos y un sentido vivo de los valores, un sentido vivo de lo bello y de lo moralmente bueno. De otra manera él -con su conocimiento especializado- se parece más a un perro amaestrado que a una persona cultivada armónicamente. Debe aprender a comprender los motivos de los seres humanos, sus ilusiones y sufrimientos para así adquirir su debida relación hacia los individuos y la comunidad. Estas cosas se transmiten a la generación joven por medio del contacto personal con quienes enseñan, y no $-\mathrm{o}$ al menos principalmente- por medio de libros de texto. Esto es lo que constituye y preserva la cultura. Esto es lo que tengo en mente cuando recomiendo las "Humanidades" como importantes, no sólo [sic] como seco conocimiento especializado en los campos de la historia y la filosofía.

Poner énfasis en el sistema... de la prematura especialización en el campo de la utilidad inmediata mata el espíritu, del cual depende toda la vida cultural, incluyendo el conocimiento especializado. (Karpinsky,1982, p. 7)

Este fue el espíritu y el pensamiento que inspiró a los gestores de la Reforma Universitaria de 1957 y que culminó con la creación de la Facultad Central de Ciencias y Letras y de su Departamento de Estudios Generales. A propósito de este departamento, decía su Director, profesor José Joaquín Trejos Fernández, en el discurso inaugural:

Los Estudios Generales propenden a ese elevado objeto: desarrollar las capacidades intelectuales, éticas y artísticas de nuestros estudiantes, de tal manera que puedan como hombres, disfrutar mejor de los bienes de una cultura elaborada durante siglos por sus antepasados, de tal manera que también puedan, como ciudadanos, disfrutar mejor de su derecho a la libertad más plena y servir a su comunidad más eficientemente. (Karpinsky,1982, p. 10)

El Departamento de Estudios Generales fue polémico y controversial, a través del tiempo logró afianzarse y consolidarse desde su proyecto inicial hasta constituirse en Escuela, como resultado del III Congreso Universitario.

Distinguidos profesionales del gremio académico costarricense fueron sus directores: el Dr. Macaya, uno de los ideólogos de la reforma universitaria de 1957, fue su primer director; el Lic. José Joaquín Trejos Fernández, Expresidente de la República, su segundo director. También lo fueron: el Dr. Claudio Gutiérrez Carranza, Rector de la Universidad de Costa Rica; el Dr. Francisco Antonio Pacheco Fernández, Rector de la Universidad Estatal a Distancia (UNED); el Lic. Guillermo Malavassi Vargas, 
Rector de la Universidad Autónoma de Centro América (UACA); el Dr. Chéster Zelaya Goodman, Rector de la UNED, así como los distinguidos académicos Dr. Víctor Manuel Arroyo Soto y el profesor Isaac Felipe Azofeifa.

El Departamento de Estudios Generales ha sido considerado el fundamento de la formación universitaria.

La convergencia: formación humana y especialísimo, constituyen un concepto que ha alcanzado vigencia en la Universidad de Costa Rica y, en general, en las grandes universidades del mundo, pues garantiza el sostenimiento de una cultura general satisfactoriamente elevada. El desentendimiento y menosprecio de este objetivo y el desinterés de algunas universidades sobre su importancia han ocasionado no solo el desprestigio de estas, sino una verdadera desnaturalización de la esencia y el espíritu de la Universidad.

Consecuente con este punto de vista, el Rector de la Universidad de Harvard: Derek Boken, en 1974 manifestó a los profesores de la "Harvard Business School" (Escuela de Negocios de Harvard), lo siguiente: “...No olviden que imparten su docencia en el marco de una Universidad cuyo fin es la Educación Integral de sus alumnos y no una fábrica de millonarios..." (Karpinsky, 1982, p. 11). Esta advertencia destaca la necesidad de que en las universidades se establezca un equilibrio entre la especialización y la formación humana del estudiante.

El advenimiento de la década de los setenta trajo consigo intenciones de cambio en la Universidad de Costa Rica. Los muchos problemas que para entonces enfrentaba dio motivo a la celebración del III Congreso Universitario (1972-1973) donde, entre otras cosas, se planteó y analizó la necesidad que tenía el país de diversificar y descentralizar la enseñanza superior mediante la apertura de nuevos centros de enseñanza, dado que el crecimiento demográfico así lo requería, pues el plantel físico era insuficiente para albergar la cada vez más creciente demanda de matrícula y, por tanto, se hacía necesario repartir la población universitaria en diferentes sectores del Área Metropolitana. En otras palabras, quedó clara la urgente necesidad de descongestionar geográfica, jurídica y administrativamente el modelo de Universidad imperante en el país hasta ese momento.

En este entorno prevaleciente, empezó a gestarse la creación de dos nuevas universidades convencionales, como resultado de un esfuerzo para enfrentar la problemática de la educación superior en el país.

El Instituto Tecnológico de Costa Rica (ITCR) con sede en Cartago, luego de una lucha por su sede en Alajuela, fue fundado en 1971. Se le asignó la enseñanza 
en el campo de la tecnología y ciencia aplicada para satisfacer las necesidades de la industria, minería, agricultura y otras áreas indispensables para incrementar la producción y el desarrollo del país. Hubo quienes se quejaron de que las altas autoridades educativas desestimaron una evaluación de aptitudes que para entonces realizó la Universidad de Costa Rica a estudiantes de las provincias de Alajuela y Cartago, que disputaron la sede del ITCR y que determinó que los alajuelenses tenían más aptitudes para las carreras técnicas.

La Universidad Nacional (UNA), con sede en la provincia de Heredia, es la tercera casa de enseñanza superior de carácter público que se funda en el país. Fue inaugurada el 14 de marzo de 1973, en el parque de Heredia, en un acto cuyo discurso principal estuvo a cargo de quien fue nombrado su primer rector, el presbítero Benjamín Núñez Vargas, y con la presencia de destacadas personalidades políticas y educativas, entre estas, Uladislao Gámez Solano, Ministro de Educación Pública, Francisco Morales Hernández, Ministro de Trabajo y Seguridad Social, y José Figueres Ferrer, Presidente de la República.

Puede afirmarse que en los primeros años de su fundación, la UNA estuvo envuelta en la polémica. Distintos personajes de la política, la educación y la prensa nacionales pusieron en tela de juicio la estructura y los principios filosóficos de la Institución. Además, se expresaron múltiples cuestionamientos de su función política y académica, así como de su primer rector, todo esto con la implícita acusación de estar dominada por la izquierda, que se dijo, tenía la intención de repudiar el enfoque académico de la Universidad de Costa Rica y sustituirlo por una orientación más práctica, encaminada hacia el cambio social.

Como respuesta a esta reacción, el presbítero Núñez auspició numerosas conferencias y numerosos debates con miras a fundamentar la labor social y educativa de la institución; en algunos casos, las discusiones tuvieron acogida en la opinión pública; en otros, se circunscribieron al ámbito institucional.

Con la apertura de estas dos universidades públicas, a comienzos de la década de los setenta, se produjo una serie de reacciones, unas favorables y otras desaprobatorias, así como analíticas, de las implicaciones que traerían a la educación superior.

El Dr. Greville Rumble, destacado funcionario de la Open University of The United of Kingdom (Universidad Abierta de la Unidad del Reino) en su obra: La UNED: una evaluación, manifiesta lo siguiente: "La fundación de estas dos universidades produjo varios problemas, particularmente en lo que se refiere a la necesidad de coordinar y racionalizar la oferta de programas académicos, 
de establecer estándares convenidos entre las instituciones y coordinar el financiamiento del sector universitario como tal" (Rumble, 1987, p. 77).

La búsqueda de solución a esta problemática dio origen en diciembre de 1974 a la fundación del Consejo Nacional de Rectores (CONARE), luego de un acuerdo alcanzado por autoridades de las tres universidades del país. Este Consejo tiene como función coordinar los programas de estudio de las tres casas de enseñanza superior y es asistido por una oficina permanente de planeamiento, la Oficina de Planificación de Educación Superior (OPES), la cual ya para 1975 elaboró el primer Plan Nacional de Educación Superior que abarcó el período comprendido desde 1976 hasta 1980. El acelerado crecimiento demográfico, aunado al insuficiente respaldo económico de los gobiernos de turno a la enseñanza superior, dio como resultado la incapacidad de las tres universidades estatales de satisfacer la demanda de matrícula, por insuficiencia de sus planteles físicos, carencia de personal administrativo y docente y falta de recursos para revisar y mejorar programas académicos.

Con estos antecedentes de fondo y como un argumento de suficiente peso, se tomó la decisión de fundar una cuarta casa de estudios superiores: la Universidad Estatal a Distancia (UNED) en 1977, una universidad para llegar a estudiantes que presentaban dificultades para asistir a alguna de las tres universidades convencionales del país. Se creó con la expectativa de que no solo ofreciera oportunidades educacionales a nuevos sectores estudiantiles, sino que además paliara en mucho la presión de la demanda social de ingreso a las universidades establecidas en una sede y aportara a la democratización y descentralización de la enseñanza superior en Costa Rica e incrementara el porcentaje general de participación, al proporcionar nuevas oportunidades educativas a los adultos y con costos unitarios estimados para este proyecto mucho menos onerosos que los de las tres universidades convencionales existentes.

Nace así la cuarta universidad estatal del país, la cual abre sus puertas en julio de 1978 con una nueva modalidad que brinda cierto grado de independencia al estudiante, en lo referente a tiempo y ubicación de sus actividades de estudio y que, a diferencia de los sistemas convencionales de enseñanza -que ponen énfasis en el aula y en el contacto inmediato presencial del profesor con los estudianteslos programas de enseñanza a distancia se caracterizan por estar constituidos por poblaciones estudiantiles relativamente dispersas y por una dependencia mínima de la enseñanza presencial. 
Así las cosas, para julio de 1978 el país cuenta con cuatro universidades públicas, tres convencionales y una cuarta con una modalidad diferente.

Sin embargo, persiste la dificultad para acceder a la educación superior, por las mismas razones expuestas. Esta continua situación desencadena la privatización de la educación superior en el país. Es así como en 1979 nace la primera universidad privada: la Universidad Autónoma de Centro América (UACA). Aparejadas a ella, emergen gran cantidad de centros de educación superior que, si bien es cierto han resuelto considerablemente la alta demanda de matrícula, también es cierto que han encarecido la enseñanza, Hay que agregar que en muchos de los casos la confiabilidad de los profesionales que gradúan no resulta ser la más competente. La razón es obvia: desean llevar agua a su molino y, para ello, entre otras cosas, necesitan contar con una nutrida población estudiantil y graduarla en el menor tiempo posible, en detrimento de la debida exigencia de sus programas académicos y, por ende, en menoscabo de la calidad y la competencia de los profesionales que salen de sus aulas.

En los primeros años de la década anterior, se empezó a agudizar el problema de la falta de trabajadores capacitados en diferentes campos de la tecnología, así como el exceso de profesionales con diferentes grados académicos en carreras muy saturadas y de escasa demanda laboral.

Era un consenso de aceptación general que el país necesitaba una entidad de enseñanza superior, que produjera técnicos profesionalmente bien capacitados, que mucha falta le estaban y le están haciendo al país para su debido desarrollo; además, prevalece la carencia de cupo en las universidades estatales por las razones expuestas en esta consideración. Al respecto, manifiesta Arguedas (2015) que “...para el año 2006, tres de las cuatro universidades públicas rechazaron el $80 \%$ de las solicitudes de admisión..." (p. 1).

Con esta situación prevaleciente en el seno de la educación superior, se presenta una propuesta inicial para crear la Universidad Técnica Nacional, mediante la fusión del Colegio Universitario de Alajuela, la Escuela Centroamericana de Ganadería, el Centro de Investigación y Perfeccionamiento para la Educación Técnica y el Centro de Formación de Formadores. Además, el Ministro de Educación Pública de ese entonces, Leonardo Garnier, propuso que se adicionaran el Colegio Universitario de Puntarenas, el Colegio Universitario para el Riego y Desarrollo del Trópico Seco y al Centro de Investigación para el Perfeccionamiento de la Educación Técnica. 
Este proyecto contó con la aprobación de las altas autoridades gubernamentales y educativas del momento y el 4 de junio del 2008 fue publicada en el Diario Oficial La Gaceta, la Ley Orgánica n. ${ }^{\circ} 8638$, que crea la Universidad Técnica Nacional, con sede central en la provincia de Alajuela. Así nace la quinta universidad pública del país, con sedes en Atenas, Pacífico y Guanacaste y una subsede en el cantón de San Carlos. En el 2009 inició lecciones con la apertura de 33 carreras de diplomado.

El Lic. Marcelo Prieto Jiménez fue nombrado su primer rector, función que aún desempeña. Para agosto del 2011, la Universidad Técnica Nacional graduó sus primeros 356 diplomados universitarios.

\section{Referencias}

Arguedas, J.A. (6 de agosto del 2015). Universidad Técnica Nacional. Recuperado de http:// www.utn.ac.cr/index.php?option $=$ com content $\&$ view $=$ article $\& i d=35 \& I t e m i d=2$

Karpinsky, R.M. (1982). Concepción teórica y práxis académica en la Universidad de Costa Rica. Universidad de Costa Rica, San José.

Rumble, G. (1987). La Universidad Estatal a Distancia: una evaluación. EUNED, San José, Costa Rica. 